\title{
Abuse-deterrent formulations of prescription opioid analgesics in the management of chronic noncancer pain
}

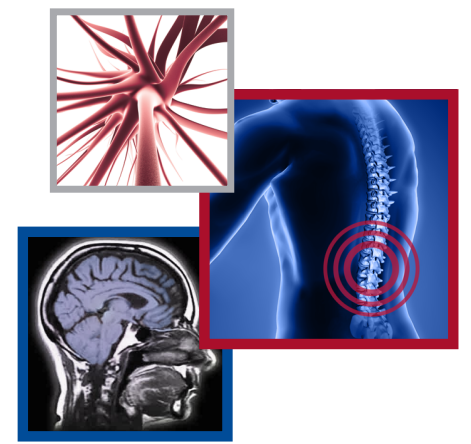

Martin E Hale ${ }^{*, 1}$, Derek Moe ${ }^{2}$, Mary Bond ${ }^{3}$, Maciej Gasior ${ }^{3} \&$ Richard Malamut ${ }^{3}$

Practice points

- Opioid analgesics are effective therapies for the management of chronic noncancer pain; however, the potential for misuse, abuse and diversion of these medications is a global public health concern.

- Strategies to minimize misuse, abuse and diversion of prescription opioid analgesics include educational and regulatory initiatives, as well as the development of novel formulations or delivery systems with abuse-deterrent properties.

- Both immediate-release and extended-release prescription opioid analgesics can be abused in their original formulation or after manipulation of the original formulation to change the drug-delivery characteristics.

- Abuse-deterrent formulations aim to hinder extraction of the active ingredient, prevent administration through alternative routes and/or make abuse of the manipulated product less attractive, less rewarding or even aversive.

- Approaches to abuse deterrence include physical and chemical barriers, agonist/antagonist combinations, aversion technologies, use of new molecular entities or prodrugs and novel delivery systems; different approaches can be combined to further reduce the potential for abuse by different routes.

- The science of abuse deterrence and the regulatory landscape are still relatively new and evolving.

- There are currently six opioid analgesics with a US FDA abuse-deterrent label, and a number of other products are under review.

- Although opioid abuse-deterrent formulations may still be abused via the intended route of administration by increasing the dose and/or dosing frequency, a growing body of evidence suggests that introduction of these formulations has been associated with decreased rates of abuse and diversion of these medications in the USA.

Misuse, abuse and diversion of prescription opioid analgesics represent a global public health concern. The development of abuse-deterrent formulations (ADFs) of prescription opioid analgesics is an important step toward reducing abuse and diversion of these medications, as well as potentially limiting medical consequences when misused or administered in error. ADFs aim to hinder extraction of the active ingredient, prevent administration through alternative routes and/or make abuse of the manipulated product less attractive, less rewarding or aversive. However, opioid ADFs may still be abused via the intended route of administration by increasing the dose and/or dosing frequency. The science of abuse
Future : Medicine ${ }_{\text {part of }}$ 


\section{KEYWORDS}

- abuse - abuse deterrence

- abuse-deterrent formulations • chronic noncancer pain - diversion - manipulation - prescription opioid analgesics

deterrence and the regulatory landscape are still relatively new and evolving. This paper reviews the current status of opioid ADFs, with particular focus on different approaches that can be used to deter abuse, regulatory considerations and implications for clinical management.

First draft submitted: 18 November 2015; Accepted for publication: 18 February 2016; Published online: 6 April 2016

Chronic noncancer pain is one of the most common reasons for seeking medical care worldwide. It has a significant impact on patients' quality of life and represents a major public health burden [1]. Data from the USA, Europe, Australia and Japan suggest that approximately $20 \%$ of the general population have chronic noncancer pain [2-8]. The Institute of Medicine estimates that 100 million North Americans have chronic noncancer pain, with associated annual direct and indirect costs exceeding US $\$ 600$ billion [9]. Low back pain - the most common cause of chronic noncancer pain - was ranked highest in terms of years lived with disability in the most recent analysis from the Global Burden of Disease Study; neck pain and other chronic musculoskeletal disorders were the fourth and tenth most common causes of years lived with disability, respectively [10].

Prescription opioid analgesics are an important treatment option for patients with chronic noncancer pain [11]. However, misuse, abuse and diversion of these medications represent a global public health concern. Misuse is defined as the intentional therapeutic use of a prescription opioid analgesic in an inappropriate way, but excluding events that meet the definition of abuse [12]. Abuse is the intentional, nontherapeutic use of a prescription opioid analgesic for the purpose of achieving a desirable psychological or physiological effect [12]. Diversion is any intentional act that results in transferring a prescription opioid analgesic from lawful to unlawful distribution or possession [12].

Abuse and misuse of prescription opioid analgesics can lead to serious consequences, including addiction, physical dependence, overdose, drug-related suicide, drug-related road traffic accidents, spreading of serious infectious diseases via shared drug paraphernalia or death [13,14]. Out of the 22,134 drug-overdose deaths involving pharmaceuticals (not including overdose of illegal drugs) that occurred during 2010 in the USA, $75.2 \%$ involved prescription opioid analgesics, frequently with concomitant use of benzodiazepines and/or alcohol [15]. Prescription opioid analgesic abuse has been independently related to risky injection behaviors, such as sharing syringes [16]. Intravenous drug users who inject prescription opioid analgesics have been shown to be more likely than those who do not inject these drugs to become infected with hepatitis $\mathrm{C}$ virus and/or human immunodeficiency virus [17-20].

Balancing the benefits of prescription opioid analgesics against their abuse liability can be challenging for clinicians. Thus, the development of abuse-deterrent formulations (ADFs) of prescription opioid analgesics is an important step toward reducing abuse and diversion of these medications, while ensuring access to these drugs for patients with legitimate medical need. ADFs may also limit the potential medical consequences if misused (e.g., if the drug is overingested, crushed or chewed before ingestion, or administered with alcohol) or taken in error. Abuse-deterrent properties are defined as those properties shown to meaningfully deter abuse, even if they do not fully prevent it. The term 'tamper-resistant' is sometimes used to describe these formulations (e.g., in Canada, where it is the preferred term), but is in fact more accurately used to describe packaging requirements applicable to certain classes of drugs, devices and cosmetics.

This paper aims to review the current status of opioid ADFs, including the different approaches used to deter abuse, regulatory considerations and available products, with implications for their use in the management of chronic noncancer pain in routine clinical practice.

\section{Scale of the problem}

Nonmedical use of prescription opioid analgesics is continuing to increase worldwide [21]. It is estimated that approximately 33 million people - or $0.7 \%$ of the world's adult population - currently abuse prescription or nonprescription opioids [21]. In the USA, approximately 4.3 million individuals aged 12 years or older ( $1.6 \%$ of the population) used prescription pain medications for nonmedical purposes in 2014 [22]. Prescription 
opioid analgesics were the second most commonly abused drug class after marijuana [22]. Indeed, it is estimated that nonmedical use of prescription opioid analgesics contributes to over 16,500 deaths annually (i.e., 46 deaths/day) in the USA [23]. In insured individuals, healthcare costs have been shown to be higher among those with a history of abuse of prescription opioid analgesics compared with those without this history $[24,25]$. The total societal cost associated with prescription opioid analgesic misuse, abuse and diversion in the USA has been estimated to range from US $\$ 55.7$ to US $\$ 72.5$ billion annually, depending on the data source [26,27]. The use of opioid ADFs would be expected to reduce, but not eradicate, this cost. Immediate-release (IR) hydrocodone is the most frequently prescribed opioid analgesic in the USA and is associated with higher rates of abuse and diversion than any other prescription opioid analgesic [28].

Although most prevalent in the USA, nonmedical use of prescription opioid analgesics is recognized to be a problem in many other parts of the world, including Canada, Australia, Europe and Japan [21,29-33]. For example, $6 \%$ of the adult population and $15.5 \%$ of secondary school students in Ontario, Canada, reported nonmedical use of prescription opioid analgesics in 2010-2011 [31]. In Australia, 7.7\% of individuals reported having used painkillers or analgesics for nonmedical purposes at some point in their lifetime [34]. Data concerning nonmedical use of prescription opioid analgesics in Europe are recognized to be scarce [35], with authorities, such as the EMA and the European Monitoring Centre on Drugs and Drug Abuse, tending to focus on rates of abuse of heroin rather than prescription opioid analgesics [33]. Nevertheless, available data indicate that nonmedical use of prescription opioid analgesics is an increasing cause for concern in this region as well $[30,33]$. In Japan, the lifetime prevalence of nonmedical use of prescription opioid analgesics has been reported to be $2.4 \%$ [36].

Prescription opioid analgesic abuse is seen in almost all age groups, from young adolescents to the elderly [22]. Diversion through family and friends appears to be the most common source of prescription opioid analgesics for abuse [37]. In most cases, these relatives and friends had obtained their prescriptions from a single doctor [37]. It should be noted that opioid abuse is a complex, multifactorial problem and $\mathrm{ADF}$ are only one potential tool to address this problem.

\section{Routes of abuse}

Prescription opioid analgesics can be abused in their original formulation or after manipulation of the original formulation to change the drugdelivery characteristics [38-40]. The aim of altering an extended-release (ER) formulation is to create a 'dose-dumping' effect (i.e., to achieve an increased maximum concentration of the opioid in the shortest time within the brain reward pathway that includes the ventral tegmental area, nucleus accumbens and cortex), which results in a rapid 'high' and other reinforcing effects that drive further abuse potential [41]. Possible routes of abuse are ingestion (including chewing or ingesting more than the usual dose), inhalation (e.g., snorting or smoking) and parenteral administration (intravenous, intramuscular or subcutaneous injection). Manipulation methods include crushing or grinding into a powder or small particles, dissolving in a solvent (e.g., alcohol), and extracting through exposure to hot or cold temperatures. To achieve enhanced CNS effects, abusers may also often co-administer prescription opioid analgesics with other psychoactive substances (e.g., alcohol, benzodiazepines, barbiturates or antidepressants) [42,43].

Data suggest that ingestion (intact or following manipulation by chewing, crushing or dissolving) is the most prevalent route of abuse for prescription opioid analgesics, followed by inhalation (snorting or smoking) and injection [38-40]. However, reported routes of abuse vary considerably between prescription opioid analgesic formulations [44]. The preferred route of abuse most likely reflects what the individual abuser finds attractive and/or unattractive about a specific formulation. ER formulations are generally more attractive to abusers than IR formulations due to the greater dose of opioid contained in the product [40]. Initial oral abuse may progress to more invasive non-oral abuse in more experienced abusers or addicted individuals [40]. Routes of abuse associated with the highest morbidity are injection and inhalation [40].

\section{Current approaches to abuse deterrence}

The goal of opioid ADFs is to maintain effective pain relief while reducing the potential for abuse by manipulation of the ER formulation. This can be achieved by hindering extraction of the active ingredient, preventing administration through alternative routes and/or making abuse of the manipulated product less attractive or less rewarding. Approaches to abuse deterrence include 
physical and chemical barriers, agonist/antagonist combinations, aversion technologies, use of new molecular entities or prodrugs and novel delivery systems (Table 1). Different approaches can be combined to further reduce the potential for abuse by different routes [45-48].

Physical and chemical barriers aim to prevent chewing, crushing, cutting, grating or grinding of the opioid formulation, and to prevent extraction of the opioid using solvents. Examples of ADFs that use physical and chemical barriers include crush-resistant pills and tablets, highviscosity gelatin capsules and extruded pellets. Formulations with these barriers may prevent multiple routes of abuse. Physical and chemical barriers have the potential to deter manipulation for abuse without the risk of adverse effects in compliant patients or those who may accidentally chew or crush their medication. However, such barriers generally do not prevent abuse of intact tablets through overingestion.

With agonist/antagonist combinations, an opioid antagonist (such as naloxone or naltrexone) is added to the formulation. Naloxone has negligible absorption after oral administration, but higher bioavailability for blockade of euphoric effects of opioids following intranasal administration or injection. Naltrexone is orally bioavailable and therefore needs to be sequestered in an oral formulation to minimize or prevent absorption from the GI tract during normal use. When used as prescribed - that is, when the product is swallowed whole or the pellets are sprinkled on food, there is no notable antagonistic effect. However, if the formulation is manipulated (e.g., crushed or chewed), the sequestered naltrexone is released, mixes with the opioid and, after being absorbed, blocks opioid receptors, which decreases the opioid euphoric and other reinforcing effects sought by the abuser. However, this may result in opioid withdrawal symptoms in opioid-dependent individuals [49-52]. Inadvertent manipulation, for example, accidental chewing, can also release the antagonist and precipitate withdrawal symptoms and reduce analgesic efficacy in compliant patients.

The aim of aversive agents is to induce unpleasant effects if the formulation is manipulated before administration or if multiple doses are consumed. Proposed aversive agents include laxatives, emetics, nauseants and bittering agents to discourage manipulation and oral overconsumption; and mucous membrane irritants to deter snorting, inhalation and/or parenteral administration. An IR formulation of oxycodone with niacin $\left(\right.$ Acurox $^{\circledR}$, Acura Pharmaceuticals, Inc.) was not approved by the US FDA due to concerns about the ease with which it was possible to circumvent the potential abuse-deterrent

Table 1. Advantages and limitations of current ADF technologies.

\begin{tabular}{|c|c|c|}
\hline ADF technology & Advantages & Limitations \\
\hline $\begin{array}{l}\text { Physical and } \\
\text { chemical barriers }\end{array}$ & $\begin{array}{l}\text { May prevent chewing, crushing, grating or grinding } \\
\text { May prevent accidental crushing or chewing in compliant } \\
\text { patients } \\
\text { May resist extraction by solvents } \\
\text { No adverse effects in compliant patients }\end{array}$ & Does not deter abuse of intact tablets \\
\hline $\begin{array}{l}\text { Agonist/antagonist } \\
\text { combinations }\end{array}$ & $\begin{array}{l}\text { Antagonist may be formulated to be clinically active only } \\
\text { when manipulated } \\
\text { May curb euphoria when formulation is compromised }\end{array}$ & $\begin{array}{l}\text { Inadvertent chewing or crushing may reduce analgesic } \\
\text { effects and/or precipitate side effects or opioid } \\
\text { withdrawal symptoms }\end{array}$ \\
\hline Aversion & $\begin{array}{l}\text { Aversive agents may be combined with the opioid to } \\
\text { create unpleasant side effects when manipulated or taken } \\
\text { at higher doses } \\
\text { May prevent abuse by chewing or crushing } \\
\text { May limit abuse of intact tablets }\end{array}$ & $\begin{array}{l}\text { Potential for unpleasant adverse effects in compliant } \\
\text { patients who take product as intended } \\
\text { Adverse effects with intact tablets may prevent legitimate } \\
\text { dose increases } \\
\text { Adverse effects may not be sufficient to deter a motivated } \\
\text { abuser }\end{array}$ \\
\hline Delivery system & $\begin{array}{l}\text { The method of drug delivery can offer resistance to abuse } \\
\text { (e.g., depot formulations or subcutaneous implants) }\end{array}$ & $\begin{array}{l}\text { It may still be possible to extract the opioid from the } \\
\text { formulation }\end{array}$ \\
\hline Prodrug & $\begin{array}{l}\text { A prodrug that lacks opioid activity until transformed } \\
\text { in the GI tract may be unattractive for intravenous or } \\
\text { intranasal routes of abuse }\end{array}$ & \\
\hline Combination & A combination of two or more of the above approaches & \\
\hline
\end{tabular}


effects of niacin, as well as the risk of side effects at therapeutic doses when used as prescribed [53]. The niacin was included to induce unpleasant flushing and other adverse reactions at excess doses; however, co-administration of food, aspirin and NSAIDs was found to attenuate these effects. A modified formulation containing an irritant instead of niacin to deter nasal administration was subsequently approved by the FDA (Oxecta $^{\mathrm{TM}}$, Pfizer, Inc.).

Prodrugs are biologically inactive substances that are metabolized inside the body to their active form. A prodrug that lacks opioid activity until it has been metabolized in the GI tract may prevent abuse via other routes of administration [53]. No currently available opioid ADFs use this approach; however, stimulant medications formulated as prodrugs are available (e.g., Vyvanse ${ }^{\circledR}$ [lisdexamfetamine], Shire Pharmaceuticals). Large-scale, postmarketing data concerning the abuse liability of this formulation are beginning to emerge, with available data showing the rate of nonmedical use of the prodrug formulation to be lower than that of short-acting stimulants and lower than or equivalent to long-acting stimulant formulations [54].

It may also be possible to formulate opioids for delivery in ways that may deter abuse, for example, as subcutaneous implants, depot injectable formulations, beads within a capsule and erodible matrix technology. Such drug delivery systems are intended to release the opioid slowly over time and are inherently difficult to manipulate.

\section{Current regulatory guidelines for ADF evaluation}

Regulatory authorities recognize that the availability of ADFs represents an important component of programs developed to address prescription opioid analgesic abuse [45,55]. The FDA guidance policy on abuse-deterrent opioid analgesics provides guidance on studies that should be conducted to demonstrate that a formulation has abuse-deterrent properties, details how those studies will be evaluated, and outlines what labeling claims may be proposed based on the results of those studies [45]. Four categories of studies are required for comprehensive product evaluation (Table 2): laboratorybased in vitro manipulation and extraction studies (Category 1), pharmacokinetic studies (Category 2), clinical abuse potential studies (Category 3) and postmarketing epidemiologic studies to determine whether use of the ADF results in a significant reduction in abuse in the community compared with conventional opioid analgesic formulations (Category 4).

The aim of Category 1 studies is to assess the ease with which the potential abuse-deterrent properties of the formulation can be overcome or compromised. These studies should consider not only how abusers may attempt to overcome the abuse-deterrent properties of the medication, but also the ways in which patients may intentionally or unintentionally alter the formulation in order to change the rate or amount of opioid released (e.g., dose dumping may occur when taking the product with alcohol or when the product is cut, chewed or crushed). The routes of abuse most likely to be used and the manipulation methods that would yield the greatest release of opioid should be used for Category 2 and 3 assessments. The effects of food and alcohol on the pharmacokinetic properties of the formulation should also be assessed. Category 4 studies represent the ultimate demonstration of ADF effectiveness; however, it may take several years to collect sufficient data to demonstrate epidemiologic impact for an individual ADF.

The FDA guidance recognizes the importance of including information on abuse-deterrent properties in the product label in order to appropriately inform healthcare professionals and the patient. The FDA suggests that the product label should not only detail the results of in vitro, pharmacokinetic, clinical abuse potential and formal postmarketing studies, but also describe the specific abuse-deterrent product features in order to appropriately characterize the abuse-deterrent properties of the product.

The draft guidelines for regulation of tamperresistant formulations issued by Health Canada are broadly similar to those from the FDA [55]. Other countries have not yet issued written guidance despite increasing awareness of the problem of abuse of prescription opioid analgesics worldwide [21,29-33].

\section{Current status of opioid analgesic ADFs}

There are currently six opioid pain medications with an FDA ADF label (Table 3). In April 2013, OxyContin ${ }^{\circledR}$ (Purdue Pharma LP) was the first opioid pain medication to be given an ADF label in the USA; it has also been available in Canada as $\mathrm{OxyNEO}^{\circledR}$ since August 2011 and in Australia as OxyContin since April 2014. This product is a reformulation of a controlled-release 
Table 2. US FDA categories of studies for characterizing abuse deterrence.

\begin{tabular}{|lll}
\hline $\begin{array}{l}\text { Category } \\
1\end{array}$ & $\begin{array}{l}\text { Study type } \\
\text { Laboratory-based in vitro manipulation } \\
\text { and extraction studies }\end{array}$ & $\begin{array}{l}\text { Goal } \\
\text { To assess the ease with which the potential abuse-deterrent properties of the } \\
\text { formulation can be overcome or compromised }\end{array}$ \\
\hline 3 & $\begin{array}{l}\text { Pharmacokinetic studies } \\
\text { pharmacokinetic profiles of intact versus manipulated formulations using one or more } \\
\text { routes of administration }\end{array}$ \\
\hline 4 & Clinical abuse potential studies & $\begin{array}{l}\text { To assess the relative abuse potential of the formulation to predict how attractive it is } \\
\text { likely to be to abusers; usually conducted in a drug-experienced population }\end{array}$ \\
\hline $\begin{array}{l}\text { ADF: Abuse-deterrent formulation. } \\
\text { Data taken from [45]. }\end{array}$ & $\begin{array}{l}\text { To determine whether use of the potential ADF results in a significant reduction in } \\
\text { abuse in the community compared with conventional opioid formulations }\end{array}$ \\
\hline
\end{tabular}

formulation of oxycodone and has physical and chemical properties intended to deter manipulation for the purposes of oral and intranasal abuse by making tablet crushing both more difficult and less effective. The formulation is also resilient to ethanol dose dumping and other chemical extraction techniques. If attempts are made to dissolve the tablet, it gradually forms a viscous gel that resists passage through a hypodermic needle, thus deterring intravenous abuse. Studies have shown this ADF to be less attractive to recreational drug abusers than the original ER formulation [56-58]. Both rate and extent of oxycodone absorption have been shown to be reduced following intranasal administration of reformulated OxyContin compared with the original formulation [57]. The reformulated OxyContin provides the same therapeutic benefits as the original formulation, which was approved by the FDA in 1995. Shipping of the original controlled-release formulation of OxyContin to wholesalers stopped in August 2010. The FDA withdrew the new drug application (NDA) for the original formulation for reasons of safety in April 2013, thereby preventing generic ER oxycodone products without an ADF from entering the market.

Approved with ADF labeling in July 2014, Targiniq $^{\text {TM }}$ ER (Purdue Pharma LP) contains oxycodone combined with naloxone - an antagonist that blocks the euphoric effects of oxycodone if the tablet is crushed for snorting or manipulated for injection [59]. The safety and effectiveness of Targiniq ER have been demonstrated in three large, 12-week, randomized, double-blind Phase III trials in patients with moderate-tosevere chronic noncancer pain [60]. However, Targiniq ER has not yet been marketed.

In October 2014, Embeda ${ }^{\circledR}$ (Pfizer, Inc.) became the third opioid analgesic to meet
FDA requirements for ADF labeling. Embeda was first approved in 2009, but was voluntarily withdrawn from the market in March 2011 due to testing that found stability concerns in the manufacturing process; it was relaunched in the USA in 2015. Embeda comprises pellets of morphine sulfate, each containing a core of sequestered naltrexone that is intended to remain sequestered when the product is taken as prescribed [61]. Studies performed in nondependent recreational opioid users have indicated that the quantity of naltrexone released upon manipulation is sufficient to attenuate the desired subjective effects of morphine following oral, intranasal or intravenous administration $[52,62,63]$.

Hysingla $^{\circledR}$ ER (Purdue Pharma LP) is a once daily formulation of hydrocodone that does not contain acetaminophen; overuse of acetaminophen is a leading cause of acute liver failure [64]. Approved in November 2014, this formulation has physical and chemical properties that render it difficult to crush, break or dissolve; these abuse-deterrent properties are expected to deter misuse and abuse via chewing, snorting and injection. Phase III studies have demonstrated the efficacy and safety of this ADF in individuals previously receiving hydrocodone/acetaminophen combination therapy for chronic pain [65]. This formulation was also shown to be well tolerated and effective for the long-term treatment of moderateto-severe chronic noncancer pain in a 12 -month open-label study [66].

MorphaBond ${ }^{\mathrm{TM}}$ ER (Inspirion Delivery Technologies), an ER formulation of morphine, is designed to present multiple barriers to abuse through widely used methods of physical and chemical manipulation without the use of antagonists or aversive agents. Laboratory test data show that, relative to morphine sulfate ER 
tablets, MorphaBond ER has increased resistance to cutting, crushing or breaking using a variety of tools. When subjected to a liquid environment, the manipulated formulation forms a viscous material that resists passage through a needle. Approved by the FDA in October 2015, MorphaBond ER is the first abuse-deterrent ER morphine product without an antagonist to be marketed in the USA [67].

Xtampza ERTM (Collegium Pharmaceuticals) is an ER oxycodone microsphere-in-capsule formulation utilizing proprietary DETERx ${ }^{\circledR}$ technology. It has been developed primarily as an ADF to protect against common methods of manipulation such as chewing, crushing, insufflation and extraction for intravenous injection. The microsphere design is also intended to enable patients with difficulty in swallowing to open the capsule and administer the contents sprinkled on food or via a feeding tube, while maintaining the ER properties of the drug [68]. Studies have shown that this formulation maintains its ER profile when crushed, making it less attractive to potential abusers [69]. In a Phase III study in opioid-naive and opioid-experienced adults with moderate-to-severe chronic low back pain, patients receiving Xtampza ER had statistically significantly lower pain scores after 12 weeks [70]. In November 2015, the FDA granted tentative approval of Xtampza ER for the management of pain severe enough to require daily, around-theclock, long-term opioid treatment and for which alternative treatment options are inadequate [71].

The FDA is currently reviewing a number of other potential opioid ADFs (Table 4). ALO-02
(Pfizer, Inc.) comprises pellets of ER oxycodone surrounding sequestered naltrexone, similar to Embeda. Crushed ALO-02 administered intranasally to nondependent recreational opioid users resulted in significantly lower drug-liking scores versus crushed IR oxycodone, suggesting lower potential for abuse [72]. ALO-02 has been shown to be effective in patients with chronic noncancer pain or chronic low back pain, with a safety profile similar to other opioids $[73,74]$.

CEP-33237 (TEVA Pharmaceutical Industries, Ltd) is an acetaminophen-free ER formulation of hydrocodone incorporating proprietary $\mathrm{CIMA}^{\circledR}$ abuse-deterrence technology utilizing multiple polymers in three mechanisms of protection via a granulation and particle-coating process [75]. CEP-33237 is designed to deter abuse via milled or crushed oral, nasal and intravenous administration and prevents dose dumping when coadministered with alcohol [76]. CEP-33237 has yielded positive results in oral and intranasal human abuse-liability studies in nondependent, recreational opioid users [77,78]. In Phase III clinical trials, CEP-33237 was shown to provide significant improvement in pain scores in patients with moderate-to-severe osteoarthritis or chronic low back pain $[79,80]$. CEP-33237 demonstrated a safety profile in these studies that was consistent with the known safety profile of hydrocodone and other opioid pain medications.

NKTR-181 (Nektar Therapeutics) is a $\mu$-opioid receptor agonist with a novel molecular structure, engineered using small molecule polymer-conjugate technology. It appears to enter the CNS at a substantially lower rate than

Table 3. Currently available opioid analgesics with a US FDA abuse-deterrent formulation label (as of January 2016).

\begin{tabular}{|c|c|c|}
\hline Drug & ADF approach & Abuse-deterrent properties \\
\hline $\begin{array}{l}\text { OxyContin }{ }^{\circledast} \\
\text { (oxycodone) }\end{array}$ & $\begin{array}{l}\text { Physical and chemical } \\
\text { barriers }\end{array}$ & $\begin{array}{l}\text { Difficult to crush or break; resistant to ethanol dose dumping and other chemical extraction } \\
\text { techniques; forms a viscous gel when dissolved }\end{array}$ \\
\hline $\begin{array}{l}\text { Targiniq }{ }^{\mathrm{TM}} \mathrm{ER} \\
\text { (oxycodone/naloxone) }\end{array}$ & $\begin{array}{l}\text { Agonist/antagonist } \\
\text { combination }\end{array}$ & $\begin{array}{l}\text { Naloxone exhibits extremely low oral bioavailability due to significant first-pass hepatic } \\
\text { metabolism, and therefore has very little effect if the product is taken orally as prescribed. } \\
\text { Naloxone is absorbed if administered intranasally or intravenously, blocking the euphoric } \\
\text { effects of oxycodone }\end{array}$ \\
\hline $\begin{array}{l}\text { Embeda }^{\oplus} \\
\text { (morphine/naltrexone) }\end{array}$ & $\begin{array}{l}\text { Agonist/antagonist } \\
\text { combination }\end{array}$ & Upon manipulation, naltrexone is released and blocks the euphoric effects of morphine \\
\hline $\begin{array}{l}\text { Hysingla }{ }^{\circledR} \mathrm{ER} \\
\text { (hydrocodone) }\end{array}$ & $\begin{array}{l}\text { Physical and chemical } \\
\text { barriers }\end{array}$ & $\begin{array}{l}\text { Difficult to crush or break; resistant to ethanol dose dumping and other chemical extraction } \\
\text { techniques; forms a viscous gel when dissolved }\end{array}$ \\
\hline $\begin{array}{l}\text { MorphaBond }{ }^{\mathrm{TM}} \mathrm{ER} \\
\text { (morphine sulfate) }\end{array}$ & $\begin{array}{l}\text { Physical and chemical } \\
\text { barriers }\end{array}$ & $\begin{array}{l}\text { Designed to present multiple barriers to abuse through widely used methods of physical } \\
\text { and chemical manipulation, as well as various routes of administration; does not contain an } \\
\text { opioid antagonist }\end{array}$ \\
\hline $\begin{array}{l}\text { Xtampza ER } \\
\text { (oxycodone) }\end{array}$ & $\begin{array}{l}\text { Physical and chemical } \\
\text { barriers }\end{array}$ & $\begin{array}{l}\text { Designed to protect against common methods of manipulation, such as chewing, rushing, } \\
\text { insufflation, and extraction for intravenous injection }\end{array}$ \\
\hline
\end{tabular}


Table 4. Potential opioid analgesic abuse-deterrent formulations under review by the US FDA (as of January 2016).

\begin{tabular}{|c|c|c|}
\hline Drug & ADF approach & Abuse-deterrent properties \\
\hline $\begin{array}{l}\text { ALO-02 } \\
\text { (oxycodone/naltrexone) }\end{array}$ & Agonist/antagonist combination & $\begin{array}{l}\text { Upon manipulation, naltrexone is released and blocks the euphoric effects of } \\
\text { morphine }\end{array}$ \\
\hline $\begin{array}{l}\text { CEP-33237 } \\
\text { (hydrocodone) }\end{array}$ & Physical and chemical barriers & $\begin{array}{l}\text { Designed to deter abuse via crushed oral, nasal and intravenous } \\
\text { administration; prevents dose dumping when co-administered with alcohol }\end{array}$ \\
\hline
\end{tabular}

traditional opioid formulations, thus making it less attractive for abuse [81]. The polymer conjugate also prevents physical and chemical manipulation. Phase III studies of NKTR-181 have been initiated in patients with chronic low back pain and chronic noncancer pain.

A number of other currently available opioid analgesics have been reported to have potential abuse-deterrent properties, but have not yet met the necessary requirements for an FDA ADF label. Examples include Exalgo ${ }^{\circledR}$ (Mallinckrodt Pharmaceuticals), Nucynta ${ }^{\circledR}$ ER (Depomed Inc.), Opana ${ }^{\circledR}$ ER (Endo Pharmaceuticals Inc.), Oxaydo ${ }^{\mathrm{TM}}$ (Egalet Corporation), Xartemis ${ }^{\mathrm{TM}}$ XR (Mallinckrodt Pharmaceuticals) and Zohydro ${ }^{\circledR}$ ER (Pernix Therapeutics) $[47,48]$.

\section{Potential impact of opioid ADFs}

A growing body of evidence suggests that introduction of opioid ADFs has been associated with decreased rates of abuse and diversion of these formulations in the USA [56,58,82-89]. In one study, an $87 \%$ reduction in overdose deaths was reported during the 3-year period following introduction of the abuse-deterrent reformulation of OxyContin [90]. Cost savings have also been reported to be associated with reductions in abuse following the introduction of the abuse-deterrent reformulation of OxyContin in the USA $[89,91,92]$. It has been estimated that reformulated oxycodone is associated with annual medical cost savings of US $\$ 430$ million and indirect cost savings of US\$605 million, giving total annual societal cost savings of approximately US $\$ 1.0$ billion [91]. The societal cost savings associated with reductions in prescription opioid analgesic abuse may be expected to increase with the introduction of other ADFs.

In some studies, however, these benefits appear to have been accompanied by a significant increase in abuse of other opioids, most notably heroin $[84,87,88,93,94]$. In one recent study, although the estimated overdose rate attributed to prescription opioid analgesics decreased by $20 \%$ during the 2 years after introduction of the abuse-deterrent reformulation of OxyContin, heroin overdose rates increased by $23 \%$ during the same period of time [88]. In another study utilizing Researched Abuse, Diversion and Addiction-Related Surveillance (RADARS) System data, rates of heroin-related deaths during 2011-2013 appeared to be inversely related to the availability of prescription opioid analgesics [58]. Such findings suggest that there is a risk that individuals may switch to abusing other prescription opioid analgesics without abuse-deterrent properties or to abusing illicit heroin. ADFs are not a treatment for addiction and it is to be expected that individuals who are addicted to opioids would switch to other opioids if their drug of choice was reformulated. However, it should be noted that rates of heroin abuse in the USA began to rise before the introduction of opioid ADFs [95]. This suggests that other factors such as increased availability and reduced costs may also have contributed to this increase, particularly since non-ADFs of prescription opioid analgesics remain widely available. Early findings from the Australian NOMAD study show that introduction of the abuse-deterrent reformulation of OxyContin in Australia was associated with a reduction in abuse by injection, with no clear switch to other drugs [96].

\section{Conclusion \& future perspective}

Opioid analgesics are effective therapies for the management of chronic noncancer pain; however, the potential for abuse and diversion of these medications is a major public health concern worldwide. Strategies to minimize abuse and diversion of prescription opioid analgesics include educational and regulatory initiatives, as well as the development of novel formulations with abuse-deterrent properties.

The science of abuse deterrence and the regulatory landscape are still relatively new and evolving. Currently available opioid ADFs have been shown to be associated with significant reductions in rates of abuse and diversion of these formulations in real-world settings, although in 
some studies, this has been accompanied by an increase in rates of heroin abuse and overdose. Furthermore, although currently available ADFs may prevent patients progressing to abuse via non-oral routes of administration, abuse by overingestion of the intact formulation is still possible. Concerns have also been expressed that the potential additional costs associated with opioid ADFs could impede access to these medications for patients with legitimate medical needs [95]. Payers may be reluctant to give preferential formulary status to branded ADFs over existing non-AD generic formulations.

ADFs clearly have particular potential benefits for certain groups of patients, such as those with a history of addiction or substance abuse, and those who live with current or recovering addicts, or with individuals who may be more likely to seek opioids for recreational use (e.g., teenagers or young adults). However, clinicians may decide to be nonselective when prescribing ADFs so as not to appear to discriminate between patients.
Financial \& competing interests disclosure

$M$ Hale is a principal investigator on clinical trials sponsored by TEVA Pharmaceutical Industries and has served as a consultant to TEVA Pharmaceutical Industries. D Moe is an employee of CIMA Labs, Inc., a subsidiary of TEVA Pharmaceutical Industries. $M$ Bond, $M$ Gasior and $R$ Malamut are employees of TEVA Pharmaceutical Industries. Other TEVA personnel provided a single medical accuracy review of the final draft. The authors have no other relevant affiliations or financial involvement with any organization or entity with a financial interest in or financial conflict with the subject matter or materials discussed in the manuscript apart from those disclosed.

Writing assistance was utilized in the production of this manuscript and was provided by Jennifer Coward of Anthemis Consulting, funded by TEVA Pharmaceutical Industries, Frazer, PA, USA.

\section{Open access}

This work is licensed under the Creative Commons Attribution-NonCommercial 4.0 Unported License. To view a copy of this license, visit http://creativecommons.org/ licenses/by-nc-nd/4.0/

\section{References}

Papers of special note have been highlighted as:

- of interest; $\bullet$ of considerable interest

1 Goldberg DS, McGee SJ. Pain as a global public health priority. BMC Public Health 11, 770 (2011).

2 Johannes CB, Le TK, Zhou X et al. The prevalence of chronic pain in United States adults: results of an Internet-based survey. J. Pain 11, 1230-1239 (2010).

3 Nakamura M, Nishiwaki Y, Ushida T, Toyama Y. Prevalence and characteristics of chronic musculoskeletal pain in Japan. J. Orthop. Sci. 16, 424-432 (2011).

4 Reid KJ, Harker J, Bala MM et al. Epidemiology of chronic non-cancer pain in Europe: narrative review of prevalence, pain treatments and pain impact. Curr. Med. Res. Opin. 27, 449-462 (2011).

5 Henderson JV, Harrison CM, Britt HC et al. Prevalence, causes, severity, impact, and management of chronic pain in Australian general practice patients. Pain Med. 14, 1346-1361 (2013).

6 Häuser W, Wolfe F, Henningsen P et al. Untying chronic pain: prevalence and societal burden of chronic pain stages in the general population - a cross-sectional survey. BMC Public Health 14, 352 (2014).

7 Dueñas M, Salazar A, Ojeda B et al. A nationwide study of chronic pain prevalence in the general Spanish population: identifying clinical subgroups through cluster analysis. Pain Med. 16, 811-822 (2015).

8 Inoue S, Kobayashi F, Nishihara M et al. Chronic pain in the Japanese community prevalence, characteristics and impact on quality of life. PLoS ONE 10, e0129262 (2015).

9 Institute of Medicine. Relieving Pain in America: A Blueprint for Transforming Prevention, Care, Education and Research. The National Academies Press, Washington, DC, USA (2011).

10 Global Burden of Disease Study 2013 Collaborators. Global, regional, and national incidence, prevalence, and years lived with disability for 301 acute and chronic diseases and injuries in 188 countries, 1990-2013: a systematic analysis for the Global Burden of Disease Study 2013 Lancet 386, 743-800 (2015).

11 Chou R, Fanciullo GJ, Fine PG et al. Clinical guidelines for the use of chronic opioid therapy in chronic noncancer pain. J. Pain 10 , 113-130 (2009).

12 Smith SM, Dart RC, Katz NP et al. Classification and definition of misuse, abuse, and related events in clinical trials: ACTTION systematic review and recommendations. Pain 154, 2287-2296 (2013).
- Consensus recommendations on classification and definition of abuse terminology.

13 Manchikanti L, Helm S, Fellows B et al. Opioid epidemic in the United States. Pain Physician 15(Suppl.), ES9-ES38 (2012).

14 Meyer R, Patel AM, Rattana SK et al. Prescription opioid abuse: a literature review of the clinical and economic burden in the United States. Popul. Health Manag. 17, 372-387 (2014).

15 Jones CM, Mack KA, Paulozzi LJ. Pharmaceutical overdose deaths, United States, 2010. JAMA. 309, 657-659 (2013).

16 Havens JR, Oser CB, Leukefeld CG. Injection risk behaviors among rural drug users: implications for HIV prevention. AIDS Care 23, 638-645 (2011).

17 Surratt H, Kurtz SP, Cicero TJ. Alternate routes of administration and risk for HIV among prescription opioid abusers. J. Addict. Dis. 30, 334-341 (2011).

18 Bruneau J, Roy E, Arruda N, Zang G, Jutras-Aswad D. The rising prevalence of prescription opioid injection and its association with hepatitis $\mathrm{C}$ incidence among street-drug users. Addiction 107, 1318-1127 (2012).

19 Conrad C, Bradley HM, Broz D et al. Community outbreak of HIV infection linked to injection drug use of oxymorphone- 
Indiana, 2015. MMWR. Morb. Mortal. Wkly Rep. 64, 443-444 (2015).

20 Lankenau SE, Kecojevic A, Silva K. Associations between prescription opioid injection and hepatitis $\mathrm{C}$ virus among young injection drug users. Drugs (Abingdon. Engl). 22, 35-42 (2015).

21 United Nations Office on Drugs and Crime. World Drug Report 2015.

www.unodc.org

- Most recent global data on drug abuse from the United Nations Office on Drugs and Crime.

22 Substance Abuse and Mental Health Services Administration, Center for Behavioral Health Statistics and Quality. Behavioral health trends in the United States: Results from the 2014 national survey on drug use and health. HHS Publication No. SMA 15-4927, NSDUH Series H-50 (2015). www.samhsa.gov

-. Most recent data from the US National Survey on Drug Use and Health.

23 Centers for Disease Control and Prevention. CDC Vitalsigns ${ }^{\mathrm{TM}}$ : Opioid painkiller prescribing (2014).

www.cdc.gov

24 Rice JB, Kirson NY, Shei A et al. The economic burden of diagnosed opioid abuse among commercially insured individuals. Postgrad. Med. 126, 53-58 (2014).

25 Rice JB, Kirson NY, Shei A et al. Estimating the costs of opioid abuse and dependence from an employer perspective: a retrospective analysis using administrative claims data. Appl. Health Econ. Health Policy 12, 435-446 (2014).

26 Birnbaum HG, White AG, Schiller M, Waldman T, Cleveland JM, Roland CL. Societal costs of prescription opioid abuse, dependence, and misuse in the United States. Pain Med. 12, 657-667 (2011).

27 Katz NP, Birnbaum H, Brennan MJ et al. Prescription opioid abuse: challenges and opportunities for payers. Am. J. Manag. Care 19, 295-302 (2013).

28 Drug Enforcement Administration. Drug Fact Sheet. Hydrocodone. www.dea.gov

29 Kuehn BM. Prescription drug abuse rises globally. JAMA 297, 1306 (2007).

30 Casati A, Sedefov R, Pfeiffer-Gerschel T. Misuse of medicines in the European Union: a systematic review of the literature. Eur. Addict. Res. 18, 228-245 (2012).

- Systematic review on the misuse of analgesics, opioid substitution medicines and sedatives/hypnotics in Europe between 2001 and 2011.

31 Fischer B, Ialomiteanu A, Boak A et al. Prevalence and key covariates of non-medical prescription opioid use among the general secondary student and adult populations in Ontario, Canada. Drug Alcohol Rev. 32 , 276-287 (2013).

32 Blanch B, Pearson SA, Haber PS. An overview of the patterns of prescription opioid use, costs and related harms in Australia. Br. J. Clin. Pharmacol. 78, 1159-1166 (2014).

33 Van Amsterdam J, van den Brink W. The misuse of prescription opioids: a threat for Europe? Curr. Drug Abuse Rev. 8, 3-14 (2015).

34 Australian Institute of Health and Welfare. National Drug Strategy Household Survey detailed report 2013 (2014). www.aihw.gov.au

35 Bramness JG, Henriksen B, Person O, Mann K. A bibliometric analysis of European versus USA research in the field of addiction. Research on alcohol, narcotics, prescription drug abuse, tobacco and steroids 2001-2011. Eur. Addict. Res. 20, 16-22 (2014).

36 Tominaga M, Kawakami N, Ono Y et al. Prevalence and correlates of illicit and non-medical use of psychotropic drugs in Japan: findings from the World Mental Health Japan Survey 2002-2004. Soc. Psychiatry Psychiatr. Epidemiol. 44, 777-783 (2009).

37 Substance Abuse and Mental Health Services Administration. Results from the 2013 national survey on drug use and health: summary of national findings (2014). www.samhsa.gov

38 Katz N, Dart RC, Bailey E et al. Tampering with prescription opioid: nature and extent of the problem, health consequences, and solutions. Am. J. Drug Alcohol Abuse 37, 205-217 (2011).

39 Kirsh K, Peppin J, Coleman J. Characterization of prescription opioid abuse in the United States: focus on route of administration. J. Pain Palliat. Care Pharmacother. 26, 348-361 (2012).

40 Gasior M, Bond M, Malamut R. Routes of abuse of prescription opioid analgesics: a review and assessment of the potential impact of abuse-deterrent formulations. Postgrad. Med. 128, 85-96 (2016).

- Recent comprehensive review on methods and routes of abuse of prescription opioid analgesics.

41 Farré M, Camí J. Pharmacokinetic considerations in abuse liability evaluation. Br. J. Addict. 86, 1601-1606 (1991).
42 Jones JD, Mogali S, Comer SD. Polydrug abuse: a review of opioid and benzodiazepine combination use. Drug Alcohol Depend. 125, 8-18 (2012).

43 Gudin JA, Mogali S, Jones JD, Comer SD. Risks, management, and monitoring of combination opioid, benzodiazepines, and/or alcohol use. Postgrad. Med. 125, 115-130 (2013).

44 Butler SF, Black RA, Cassidy TA et al. Abuse risks and routes of administration of different prescription opioid compounds and formulations. Harm. Reduct. J. 8, 29 (2011).

45 US Food and Drug Administration. Abuse-deterrent opioids - evaluation and labeling guidance for industry (2015). www.fda.gov

-• Current US FDA guidelines concerning the development and labeling of abuse-deterrent opioid formulations.

46 Stanos SP, Bruckenthal P, Barkin RL. Strategies to reduce the tampering and subsequent abuse of long-acting opioids: potential risks and benefits of formulations with physical or pharmacologic deterrents to tampering. Mayo Clin. Proc. 87, 683-694 (2012).

47 Mastropietro DJ, Omidian H. Abusedeterrent formulations: part 1 - development of a formulation-based classification system. Expert Opin. Drug Metab. Toxicol. 11, 193-204 (2015).

48 Mastropietro DJ, Omidian H. Abusedeterrent formulations: part 2: commercial products and proprietary technologies. Expert Opin. Pharmacother. 16, 305-323 (2015).

49 Jang DH, Rohe JC, Hoffman RS, Nelson LS. Severe opioid withdrawal due to misuse of new combined morphine and naltrexone product (Embeda). Ann. Emerg. Med. 55, 303-304 (2010).

50 Ruan X, Chen T, Gudin J, Couch JP, Chiravuri S. Acute opioid withdrawal precipitated by ingestion of crushed Embeda (morphine extended release with sequestered naltrexone): case report and the focused review of the literature. J. Opioid Manag. 6, 300-303 (2010).

51 Badalamenti VC, Buckley JW, Smith ET. Safety of EMBEda (morphine sulfate and naltrexone hydrochloride) extended-release capsules: review of postmarketing adverse events during the first year. J. Opioid. Manag. 8, 115-125 (2012).

52 Setnik B, Roland CL, Goli V et al. A clinical trial to determine if corelease of morphine and naltrexone from crushed extended-release capsules induces withdrawal in opioid- 
dependent patients: a descriptive analysis of six patients. J. Opioid Manag. 9, 139-150 (2013).

53 Schaeffer T. Abuse-deterrent formulations, an evolving technology against the abuse and misuse of opioid analgesics. J. Med. Toxicol. 8 , 400-407 (2012).

54 Coghill DR, Caballero B, Sorooshian S, Civil R. A systematic review of the safety of lisdexamfetamine dimesylate. CNS Drugs 28, 497-511 (2014)

55 Health Canada. Draft Guidance Document. Tamper-resistant formulations of opioid drug product submissions.

www.hc-sc.gc.ca

- Draft Canadian guidelines concerning the development and labeling of abuse-deterrent opioid formulations.

56 Sellers EM, Perrino PJ, Colucci SV, Harris SC. Attractiveness of reformulated OxyContin ${ }^{\circledR}$ tablets: assessing comparative preferences and tampering potential. J. Psychopharmacol. 27, 808-816 (2013).

57 Harris SC, Perrino PJ, Smith I et al. Abuse potential, pharmacokinetics,

pharmacodynamics, and safety of intranasally administered crushed oxycodone $\mathrm{HCl}$ abuse-deterrent controlled-release tablets in recreational opioid users. J. Clin. Pharmacol. 54, 468-477 (2014).

58 Dart RC, Surratt HL, Cicero TJ et al. Trends in opioid analgesic abuse and mortality in the United States. N. Engl. J. Med. 372, 241-248 (2015).

- Analysis of data from the Researched Abuse, Diversion, and Addiction-Related Surveillance (RADARS) System to describe trends in the diversion and abuse of prescription opioid analgesics from January 2002 through December 2013.

59 Colucci SV, Perrino PJ, Shram M et al. Abuse potential of intravenous oxycodone/naloxone solution in nondependent recreational drug users. Clin. Drug. Investig. 34, 421-429 (2014).

60 Burness CB, Keating GM. Oxycodone/ naloxone prolonged-release: a review of its use in the management of chronic pain while counteracting opioid-induced constipation. Drugs 74, 353-375 (2014).

61 Katz N, Sun S, Johnson F, Stauffer J. ALO-01 (morphine sulfate and naltrexone hydrochloride) extended release capsules in the treatment of chronic pain of osteoarthritis of the hip or knee: pharmacokinetics, efficacy, and safety. J. Pain 11, 303-311 (2010).
62 Stauffer J, Setnik B, Sokolowska M et al. Subjective effects and safety of whole and tampered morphine sulfate and naltrexone hydrochloride (ALO-01) extended-release capsules versus morphine solution and placebo in experienced non-dependent opioid users: a randomized, double-blind, placebocontrolled, crossover study. Clin. Drug Investig. 29, 777-790 (2009).

63 Webster LR, Johnson FK, Stauffer J et al. Impact of intravenous naltrexone on intravenous morphine-induced high, drug liking, and euphoric effects in experienced, nondependent male opioid users. Drugs R D 11, 259-275 (2011)

64 Tiegs G, Karimi K, Brune K, Arck P. New problems arising from old drugs: secondgeneration effects of acetaminophen. Expert Rev. Clin. Pharmacol. 7, 655-662 (2014).

65 Bartoli A, Michna E, He E, Wen W. Efficacy and safety of once-daily, extended-release hydrocodone in individuals previously receiving hydrocodone/acetaminophen combination therapy for chronic pain. Postgrad. Med. 127, 5-12 (2015).

66 Wen W, Taber L, Lynch SY et al. 12-Month safety and effectiveness of once-daily hydrocodone tablets formulated with abuse-deterrent properties in patients with moderate to severe chronic pain. J. Opioid Manag. 11, 339-356 (2015).

67 Inspiron Delivery Technologies LLC. Inspirion Delivery Technologies receives FDA approval for MorphaBond ${ }^{\mathrm{TM}}$ (morphine sulfate) extended-release tablets CII, an opioid analgesic formulated with abuse-deterrent properties (2015).

www.prnewswire.com

68 Fleming AB, Carlson DR, Varanasi RK et al. Evaluation of an extended-release, abusedeterrent, microsphere-in-capsule analgesic for the management of patients with chronic pain with dysphagia (CPD). Pain Pract. 16(3), 334-344 (2015).

69 Gudin J, Levy-Cooperman N, Kopecky EA, Fleming AB. Comparing the effect of tampering on the oral pharmacokinetic profiles of two extended-release oxycodone formulations with abuse-deterrent properties. Pain Med. 16, 2142-2151 (2015).

70 Katz N, Kopecky EA, O'Connor M et al. A Phase 3, multi-center, randomized, double-blind, placebo-controlled, safety, tolerability, and efficacy study of Xtampza ER $^{\mathrm{TM}}$ in patients with moderate-to-severe chronic low back pain. Pain 156, 2458-2467 (2015).

71 Collegium announces FDA tentative approval for Xtampza ${ }^{\mathrm{TM}} \mathrm{ER}$, a novel abuse-deterrent analgesic for chronic pain (2015).

http://globenewswire.com

72 Setnik B, Bramson C, Bass A et al. Intranasal administration of crushed ALO-02 (extended-release oxycodone with sequestered naltrexone): A randomized, controlled, abuse potential study in nondependent recreational opioid users. J. Clin. Pharmacol. 55, 1351-1361 (2015).

73 Arora S, Setnik B, Michael D et al. A multicenter, 12-month, open-label, single-arm safety study of oxycodone-hydrochloride/ naltrexone-hydrochloride extended-release capsules (ALO-02) in patients with moderate-to-severe chronic noncancer pain. J. Opioid. Manag. 10, 423-436 (2014).

74 Rauck RL, Hale ME, Bass A et al. A randomized double-blind, placebo-controlled efficacy and safety study of ALO-02 (extended-release oxycodone surrounding sequestered naltrexone) for moderate-tosevere chronic low back pain treatment. Pain 156, 1660-1669 (2015).

75 CIMA LABS, Inc. OraGuard ${ }^{\mathrm{TM}}$ : tamperdeterrent, alcohol-resistant extended release technology (2012). www.cimalabs.com/technology/oraguard

76 Darwish M, Bond M, Yang R et al. Assessment of alcohol-induced dose dumping with a hydrocodone bitartrate extendedrelease tablet formulated with CIMA $^{\circledR}$ abuse deterrence technology. Clin. Drug Investig. 35 , 645-652 (2015).

77 Darwish M, Bond M, Tracewell W, Robertson P. Evaluation of the abuse potential of an extended release hydrocodone bitartrate tablet formulated with OraGuard ${ }^{\mathrm{TM}}$ technology in non-dependent, recreational opioid users. J. Pain 14, S74 (2013) (Abstract 395).

78 Bond M, Schoedel C, Rabinovich-Guilatt L et al. Evaluation of the relative intranasal abuse potential of a hydrocodone extended-release tablet formulated with abuse-deterrence technology in nondependent, recreational opioid users. J. Pain 16, S82 (2015) (Abstract 425).

79 Hale ME, Laudadio C, Yang R et al. Efficacy and tolerability of a hydrocodone extendedrelease tablet formulated with abusedeterrence technology for the treatment of moderate-to-severe chronic pain in patients with osteoarthritis or low back pain. J. Pain Res. 8, 623-636 (2015).

80 Hale ME, Zimmerman TR, Eyal E, Malamut R. Efficacy and safety of a hydrocodone extended-release tablet formulated with abuse-deterrence technology in patients with moderate-to-severe chronic low back pain. J. Opioid Manag. 11, 507-518 (2015). 
81 Webster LR, Smith S, Silowsky J et al. Abuse potential assessment of novel opioid analgesic NKTR-181: implications for labelling and scheduling. Drug Alcohol Depend. 140, e239 (2014).

82 Cicero TJ, Ellis MS, Surratt HL. Effect of abuse-deterrent formulation of OxyContin. N. Engl. J. Med. 367, 187-189 (2012).

83 Butler SF, Cassidy TA, Chilcoat $\mathrm{H}$ et al. Abuse rates and routes of administration of reformulated extended-release oxycodone: initial findings from a sentinel surveillance sample of individuals assessed for substance abuse treatment. J. Pain 14, 351-358 (2013).

- Analysis of the impact of the availability of an abuse-deterrent formulation of oxycodone on abuse rates and routes of abuse.

84 Coplan PM, Kale H, Sandstrom L et al. Changes in oxycodone and heroin exposures in the National Poison Data System after introduction of extended-release oxycodone with abuse-deterrent characteristics. Pharmacoepidemiol. Drug. Saf. 22, 1274-1282 (2013).

85 Severtson SG, Bartelson BB, Davis JM et al. Reduced abuse, therapeutic errors, and diversion following reformulation of extended-release oxycodone in 2010. J. Pain 14, 1122-1130 (2013).

86 Havens JR, Leukefeld CG, DeVeaugh-Geiss AM et al. The impact of a reformulation of extended-release oxycodone designed to deter abuse in a sample of prescription opioid abusers. Drug Alcohol Depend. 139, 9-17 (2014).

87 Cicero TJ, Ellis MS. Abuse-deterrent formulations and the prescription opioid abuse epidemic in the United States: lessons learned from OxyContin. JAMA Psychiat. 72, 424-430 (2015)

88 Larochelle MR, Zhang F, Ross-Degnan D, Wharam JF. Rates of opioid dispensing and overdose after introduction of abuse-deterrent extended-release oxycodone and withdrawal of propoxyphene. JAMA. Intern. Med. 175, 978-987 (2015).

89 White AG, LeCates J, Birnbaum HG et al. Positive subjective measures in abuse liability studies and real-world nonmedical use: potential impact of abuse-deterrent opioids on rates of nonmedical use and associated healthcare costs. J. Opioid Manag. 11, 199-210 (2015).

90 Sessler NE, Downing JM, Kale $\mathrm{H}$ et al. Reductions in reported deaths following the introduction of extended-release oxycodone (OxyContin) with an abuse-deterrent formulation. Pharmacoepidemiol. Drug Saf. 23, 1238-1246 (2014).

91 Kirson NY, Shei A, White AG et al. Societal economic benefits associated with an extended-release opioid with abuse-deterrent technology in the United States. Pain Med. 15, 1450-1454 (2014).

92 Rossiter LF, Kirson NY, Shei A et al. Medical cost savings associated with an extendedrelease opioid with abuse-deterrent technology in the US. J. Med. Econ. 17, 279-287 (2014).

93 Cassidy TA, DasMahapatra P, Black RA et al. Changes in prevalence of prescription opioid abuse after introduction of an abuse-deterrent opioid formulation. Pain Med. 15, 440-451 (2014).

94 Cicero TJ, Ellis MS, Harney J. Shifting patterns of prescription opioid and heroin abuse in the United States. N. Engl. J. Med. 373, 1789-1790 (2015).

95 Simon K, Worthy SL, Barnes MC, Tarbell B. Abuse-deterrent formulations: transitioning the pharmaceutical market to improve public health and safety. Ther. Adv. Drug. Saf. 6, 67-79 (2015).

- Overview of abuse-deterrent formulations as a method to reduce prescription opioid abuse, including policy recommendations for transitioning the market.

96 Degenhardt L, Bruno R, Ali R et al. The introduction of a potentially abuse deterrent oxycodone formulation: early findings from the Australian National Opioid Medications Abuse Deterrence (NOMAD) study. Drug Alcohol Depend. 151, 56-67 (2015). 